\title{
FUNGSI EVANS, SIFAT-SIFAT DAN APLIKASINYA PADA PELACAKAN NILAI EIGEN DARI MASALAH STURM-LIOUVILLE
}

\author{
HILDA FAHLENA, MAHDHIVAN SYAFWAN, ADMI NAZRA \\ Program Studi Matematika, \\ Fakultas Matematika dan Ilmu Pengetahuan Alam, Universitas Andalas, \\ Kampus UNAND Limau Manis Padang, Indonesia, \\ hildafahlena92@gmail.com
}

\begin{abstract}
Abstrak. Pada paper ini dikonstruksi dan didefinisikan fungsi Evans pada masalah Sturm-Liouville. Beberapa sifat-sifat fungsi Evans juga dibuktikan, yaitu: (i) nilai nolnya berkaitan dengan nilai eigen, (ii) analitik untuk semua nilai eigen yang bernilai kompleks, dan (iii) mempunyai simple zeros pada kasus khusus dari masalah Sturm-Liouville. Sifatsifat fungsi Evans tersebut kemudian diterapkan untuk melacak nilai eigen dari masalah Sturm-Liouville.
\end{abstract}

Kata Kunci: Fungsi Evans, masalah Sturm-Liouville, nilai eigen, analitik, simple zeros

\section{Pendahuluan}

Diberikan masalah Sturm-Liouville berikut ini [1]:

$$
-\frac{d}{d x}\left(p(x) \frac{d y(x)}{d x}\right)+q(x) y(x)=\lambda w(x) y(x), \quad-L \leq x \leq L,
$$

dengan syarat batas yang memenuhi

$$
a_{1} y(-L)+b_{1} \frac{d y(-L)}{d x}=0,
$$

dan

$$
a_{2} y(L)+b_{2} \frac{d y(L)}{d x}=0 .
$$

Pada persamaan (1.2) dan (1.3), konstanta $a_{j}, b_{j}$, untuk $j=1,2$, bernilai riil dan memenuhi hubungan

$$
a_{1}^{2}+b_{1}^{2}=a_{2}^{2}+b_{2}^{2}=1 .
$$

Koefisien $p(x)>0$ pada persamaan (1.1) diasumsikan mulus dan bernilai riil, sedangkan koefisien $q(x)$ dan $w(x)$ dapat bernilai kompleks dan diasumsikan mulus bagian demi bagian.

Masalah Sturm-Liouville (1.1) muncul ketika metode pemisahan variabel digunakan dalam menyelesaikan suatu persamaan diferensial parsial linier orde 2, diantaranya persamaan panas, persamaan gelombang, dan persamaan transport [1].

Tujuan dalam menyelesaikan masalah Sturm-Liouville (1.1 - 1.3) adalah untuk menentukan nilai eigen $\lambda$, yang darinya terdapat solusi nontrivial untuk $y(x)$. Suatu 
solusi nontrivial yang berkaitan dengan suatu nilai eigen dikenal sebagai fungsi eigen.

Pada paper ini akan dibahas sebuah fungsi, yang disebut fungsi Evans, yang analitik di bidang kompleks $\lambda$, dan memiliki sifat bahwa nilai nolnya bersesuaian secara tepat dengan nilai eigen. Kajian pada paper ini mengeksplorasi kembali studi pada referensi [1].

\section{Landasan Teori}

\subsection{Penurunan masalah Sturm-Liouville}

Bentuk umum dari persamaan diferensial parsial (PDP) linier orde dua diberikan oleh

$f(x) \frac{\partial^{2} r(x, t)}{\partial x^{2}}+g(x) \frac{\partial r(x, t)}{\partial x}+h(x) r(x, t)=l(t) \frac{\partial^{2} r(x, t)}{\partial t^{2}}+m(t) \frac{\partial r(x, t)}{\partial t}+n(t) r(x, t)$,

dimana $-L \leq x \leq L$ dan $t>0$. Berikut ini adalah beberapa contoh PDP linier orde dua yang paling sederhana dan sering dipelajari [4]:

(1) Persamaan panas : $r_{t}=d^{2} r_{x x}$

(2) Persamaan gelombang : $r_{t t}=c^{2} r_{x x}$.

(3) Persamaan transport : $r_{t}=c r_{x}$.

Konstanta $d^{2}$ pada persamaan panas menyatakan difusivitas termal, sedangkan konstanta $c$ pada persamaan gelombang dan transport menyatakan kecepatan.

Pada subbab ini akan dibahas penurunan masalah Sturm-Liouville $(1.1-1.3)$ dari persamaan (2.1). Dalam hal ini, syarat batas yang digunakan adalah

$$
a_{1} r(-L, t)+b_{1} r_{x}(-L, t)=0
$$

dan

$$
a_{2} r(L, t)+b_{2} r_{x}(L, t)=0,
$$

dimana

$$
a_{1}^{2}+b_{1}^{2}=a_{2}^{2}+b_{2}^{2}=1 .
$$

Dengan menggunakan metode pemisahan variabel, yaitu dengan mengasumsikan $r(x, t)$ sebagai hasil kali dari dua fungsi, yang satu bergantung pada $x$ dan yang lain bergantung pada $t$, maka dapat ditulis

$$
r(x, t)=y(x) s(t) .
$$

Substitusikan (2.5) ke persamaan (2.1), diperoleh

$$
\frac{\mathcal{L} y(x)}{y(x)}=\frac{\mathcal{M} s(t)}{s(t)}
$$

dimana operator $\mathcal{L}$ dan $\mathcal{M}$ didefinisikan oleh

$$
\begin{aligned}
\mathcal{L} & =f(x) \frac{d^{2}}{d x^{2}}+g(x) \frac{d}{d x}+h(x), \\
\mathcal{M} & =l(t) \frac{d^{2}}{d t^{2}}+m(t) \frac{d}{d t}+n(t) .
\end{aligned}
$$


Karena $\mathcal{L}$ dan $y(x)$ tidak bergantung pada $t$, sedangkan $\mathcal{M}$ dan $s(t)$ tidak bergantung pada $x$, maka kedua sisi persamaan (2.6) mestilah sama dengan suatu konstanta yang tak-nol, katakanlah $\lambda$. Jadi diperoleh dua persamaan,

$$
\begin{aligned}
\mathcal{L} y(x) & =\lambda y(x), \\
\mathcal{M} s(t) & =\lambda s(t) .
\end{aligned}
$$

Kemudian kalikan kedua sisi persamaan (2.7) dengan $w(x) \neq 0$ dan misalkan

$$
\begin{gathered}
p(x)=f(x) w(x), \\
\frac{d p(x)}{d x}=g(x) w(x), \\
q(x)=h(x) w(x) .
\end{gathered}
$$

Dengan demikian diperoleh

$$
p(x) \frac{d^{2} y(x)}{d x}+\frac{d p(x)}{d x} \frac{d y(x)}{d x}+q(x) y(x)=\lambda w(x) y(x),
$$

yang sama persis dengan persamaan (1.1). Kemudian substitusi persamaan (2.5) ke persamaan (2.2) dan (2.3) berturut-turut menghasilkan persamaan syarat batas (1.2) dan (1.3).

\subsection{Simple Zeros}

Berikut ini diberikan definisi nol dengan orde $k$ dan simple zeros.

Definisi 2.1. [3] Suatu fungsi kompleks $f(z)$ yang analitik pada D dikatakan mempunyai nol dengan orde $k$ di titik $z=\alpha$ jika memenuhi

$$
f^{(n)}(\alpha)=0, \text { untuk } n=0,1, \cdots, k-1 \text {, dengan } k \in \mathbb{N}
$$

dan

$$
f^{(k)}(\alpha) \neq 0
$$

Jika $k=1$, maka $f(z)$ dikatakan mempunyai simple zeros.

\section{Konstruksi Fungsi Evans}

Pandang kembali masalah Sturm-Liouville yang diberikan oleh persamaan (1.1 1.3). Masalah tersebut terlebih dahulu akan diformulasikan dalam bentuk vektor agar perspektif geometrisnya lebih dapat dilihat. Misalkan

$$
u(x)=y(x), \quad v(x)=p(x) \frac{d y(x)}{d x} .
$$

Dengan menggunakan pemisalan (3.1), persamaan (1.1) dapat ditulis dalam bentuk persamaan matriks sebagai berikut:

$$
\frac{d}{d x}\left(\begin{array}{c}
u \\
v
\end{array}\right)=A(x ; \lambda)\left(\begin{array}{l}
u \\
v
\end{array}\right)
$$


dimana

$$
A(x ; \lambda)=\left(\begin{array}{cc}
0 & \frac{1}{p} \\
(q-\lambda w) & 0
\end{array}\right) .
$$

Jadi syarat batas (1.2) dan (1.3) dapat ditulis

$$
\left(\begin{array}{c}
u(-L) \\
v(-L)
\end{array}\right)=k_{1}\left(\begin{array}{c}
-\frac{b_{1}}{p(-L)} \\
a_{1}
\end{array}\right), \quad\left(\begin{array}{l}
u(L) \\
v(L)
\end{array}\right)=k_{2}\left(\begin{array}{c}
-\frac{b_{2}}{p(L)} \\
a_{2}
\end{array}\right),
$$

dimana $k_{1}$ dan $k_{2}$ adalah konstanta-konstanta sebarang yang tak-nol.

Untuk menentukan nilai-nilai eigen, maka sistem persamaan diferensial (3.2) akan diselesaikan dengan syarat awalnya adalah syarat batas di $x=-L$. Kemudian akan dilihat seberapa dekat solusinya memenuhi syarat batas di $x=L$. Untuk mengukur sebe-rapa dekat solusi ini, maka digunakan determinan dari matriks solusi fundamental yang memenuhi kedua syarat batas di $x=L$ dan $x=-L$. Determinan inilah yang disebut dengan fungsi Evans. Jika solusi tersebut memenuhi kedua syarat batas di $x= \pm L$, maka determinannya bernilai nol.

Misalkan

$$
\phi(x ; \lambda)=\left(\begin{array}{cc}
u(x ; \lambda) & \tilde{u}(x ; \lambda) \\
v(x ; \lambda) & \tilde{v}(x ; \lambda) ;
\end{array}\right)
$$

adalah sebuah matriks solusi fundamental dari sistem (3.2) yang memenuhi syarat awal di $x=-L$. Dengan kata lain, $\phi(x ; \lambda)$ didefinisikan melalui

$$
\frac{\partial}{\partial x} \phi=A(x ; \lambda) \phi, \quad \phi(-L ; \lambda)=\left(\begin{array}{cc}
-\frac{b_{1}}{p(-L)} & c a_{1} \\
a_{1} & \frac{c b_{1}}{p(-L)}
\end{array}\right),
$$

dimana

$$
c=-\frac{1}{\left(\frac{b_{1}}{p(-L)}\right)^{2}+a_{1}^{2}}<0
$$

adalah konstanta tak-nol sedemikian sehingga $\operatorname{det}(\phi(-L ; \lambda))=1$. Karena $\operatorname{tr}(A(x ; \lambda))=0$, maka dengan menggunakan formula Abel diperoleh

$$
\operatorname{det}(\phi(x ; \lambda))=\operatorname{det}(\phi(-L ; \lambda)) \mathrm{e}^{\int_{-L}^{x} \operatorname{tr}(\mathrm{A}(s ; \lambda)) d s}=1 .
$$

Selanjutnya perhatikan bahwa solusi dari sistem (3.2) yang diberikan oleh

$$
\left(\begin{array}{l}
u(x ; \lambda) \\
v(x ; \lambda)
\end{array}\right)=\phi(x ; \lambda)\left(\begin{array}{l}
1 \\
0
\end{array}\right)
$$

memenuhi syarat batas di $x=-L$. Jika solusi ini juga memenuhi syarat batas di $x=L$, maka $\lambda$ merupakan nilai eigen. Observasi ini membawa kita pada definisi fungsi Evans berikut ini.

Definisi 3.1. [1] Fungsi Evans, yang dinotasikan dengan $E(\lambda)$, didefinisikan oleh

$$
E(\lambda)=\operatorname{det}\left(\phi(L ; \lambda)\left(\begin{array}{c}
1 \\
0
\end{array}\right) \begin{array}{c}
-\frac{b_{2}}{p(L)} \\
a_{2}
\end{array}\right),
$$

dimana $\phi(x ; \lambda)$ adalah matriks solusi fundamental yang memenuhi sistem (3.5). 


\section{Sifat-sifat Fungsi Evans}

Pada subbab ini akan ditunjukkan beberapa sifat fungsi Evans yang akan berguna untuk analisis masalah Sturm-Liouville nantinya. Sifat-sifat tersebut diberikan pada teorema-teorema berikut.

Teorema 4.1. [1] Nilai $\lambda=\alpha$ adalah solusi dari $E(\lambda)=0$ jika dan hanya jika $\lambda=\alpha$ adalah nilai eigen.

Bukti. $(\Rightarrow)$ Jika $\lambda=\alpha$ adalah solusi dari $E(\lambda)=0$, maka dari definisi determinan haruslah berlaku

$$
\phi(L ; \alpha)\left(\begin{array}{c}
1 \\
0
\end{array}\right)=\hat{c}\left(\begin{array}{c}
-\frac{b_{2}}{p(L)} \\
a_{2}
\end{array}\right), \hat{c} \neq 0 .
$$

Perhatikan bahwa sisi kanan dari persamaan (4.1) adalah vektor yang sejajar dengan vektor yang memenuhi syarat batas di $x=L$ [lihat persamaan (3.3)]. Akibatnya $\lambda=\alpha$ adalah nilai eigen.

$(\Leftarrow)$ Jika $\lambda=\alpha$ adalah nilai eigen, maka solusi dari persamaan diferensial yang memenuhi syarat batas di $x=-L$ haruslah juga memenuhi syarat batas di $x=L$. Hal ini berakibat

$$
E(\lambda)=\operatorname{det}\left(\begin{array}{cc}
\frac{-k_{2} b_{2}}{p(L)} & \frac{-b_{2}}{p(L)} \\
k_{2} a_{2} & a_{2}
\end{array}\right)=0
$$

Teorema 4.2. [1] Misalkan fungsi Evans $E(\lambda)$ untuk $\lambda=x+\mathrm{i} y, x, y \in \mathbb{R}$, dapat ditulis $E(\lambda)=U(x, y)+\mathrm{i} V(x, y)$ dimana $U_{x}, U_{y}, V_{x}$, dan $V_{y}$ kontinu. Maka $E(\lambda)$ analitik untuk setiap $\lambda \in \mathbb{C}$.

Bukti. Diketahui bahwa fungsi Evans $E(\lambda)=U(x, y)+\mathrm{i} V(x, y)$ mempunyai $U_{x}, U_{y}, V_{x}$, dan $V_{y}$ yang kontinu. Jadi untuk menunjukkan $E(\lambda)$ analitik, cukup ditunjukkan $\frac{\partial}{\partial \lambda} E(\lambda)=0$ untuk setiap $\lambda \in \mathbb{C}$ (lihat [3]).

Karena nilai $\lambda$ pada fungsi Evans hanya bergantung pada matriks solusi fundamental $\phi(x ; \lambda)$, maka

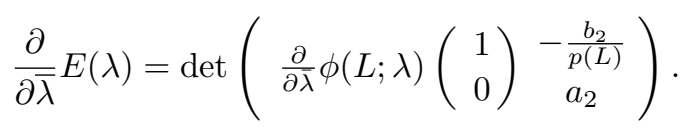

Dengan demikian, cukup ditunjukkan bahwa

$$
\frac{\partial}{\partial \bar{\lambda}} \phi(L ; \lambda)=\mathbf{0}_{2}
$$

dimana $\mathbf{0}_{2}$ adalah matriks nol berukuran $2 \times 2$. Sekarang pandang persamaan $(3.5)$ dan perhatikan bahwa

$$
\frac{\partial}{\partial \bar{\lambda}}\left(\frac{\partial}{\partial x} \phi(x ; \lambda)\right)=\frac{\partial A(x ; \lambda)}{\partial \bar{\lambda}} \phi(x ; \lambda)+A(x ; \lambda) \frac{\partial \phi(x ; \lambda)}{\partial \bar{\lambda}}, \quad \frac{\partial}{\partial \bar{\lambda}} \phi(-L ; \lambda)=\mathbf{0}_{2} .
$$


Dengan memisalkan $\psi(x)=\frac{\partial}{\partial \bar{\lambda}} \phi$, dan dari kenyataan bahwa $\frac{\partial A(x ; \lambda)}{\partial \bar{\lambda}}=0$, persamaan (4.4) dapat ditulis kembali menjadi

$$
\frac{\partial}{\partial x} \psi(x)=A(x ; \lambda) \psi(x ; \lambda), \quad \psi(-L)=\mathbf{0}_{2} .
$$

Solusi dari sistem di atas adalah $\psi(x) \equiv \mathbf{0}_{2}$, sehingga berlaku

$$
\psi(x)=\mathbf{0}_{2} \Rightarrow \frac{\partial}{\partial \bar{\lambda}} \phi(L ; \lambda)=\mathbf{0}_{2} .
$$

Teorema 4.3. [1] Jika $p, q$, dan w pada masalah Sturm-Liouville (1.1--1.3) bernilai riil dengan $p, w>0$, maka solusi riil dari $E(\lambda)=0$ adalah simple zeros.

Bukti. Berdasarkan definisi simple zeros (lihat Definisi 2.1), maka akan ditunjukkan bahwa turunan (pertama) dari fungsi Evans tidak nol di titik dimana fungsi Evans bernilai nol. Dengan mengambil turunan terhadap $\lambda$ pada persamaan (3.5) dan menggunakan aturan hasil kali, diperoleh

$$
\frac{\partial}{\partial \lambda}\left(\frac{\partial}{\partial x} \phi\right)=\frac{\partial A}{\partial \lambda} \phi+A \frac{d \phi}{\partial \lambda}, \quad \frac{\partial}{\partial \lambda} \phi(-L ; \lambda)=\mathbf{0}_{2} .
$$

Misalkan

$$
\psi=\frac{\partial}{\partial \lambda} \phi
$$

maka persamaan (4.7) menjadi

$$
\frac{\partial}{\partial \lambda} \psi=A \psi+\frac{\partial A}{\partial \lambda} \phi, \quad \psi(-L ; \lambda)=\frac{\partial}{\partial \lambda} \phi(-L ; \lambda)=\mathbf{0}_{2} .
$$

Dengan menerapkan metode variasi parameter dalam menyelesaikan sistem di atas, diperoleh

$$
\psi(x ; \lambda)=\phi(x ; \lambda) \int_{-L}^{x} \phi(s ; \lambda)^{-1} \frac{\partial A}{\partial \lambda} \phi(s ; \lambda) d s .
$$

Karena $\operatorname{det}(\phi)=1$, maka berlaku

$$
\phi=\left(\begin{array}{ll}
u & \tilde{u} \\
v & \tilde{v}
\end{array}\right) \Rightarrow \phi^{-1}=\left(\begin{array}{rr}
\tilde{v} & -\tilde{u} \\
-v & u
\end{array}\right) .
$$

Dengan mensubstitusikan invers di atas ke persamaan (4.10), diperoleh

$$
\begin{aligned}
\psi(L ; \lambda)\left(\begin{array}{l}
1 \\
0
\end{array}\right) & =\phi(L ; \lambda) \int_{-L}^{L} \phi(s ; \lambda)^{-1} \frac{\partial A}{\partial \lambda} \phi(s ; \lambda) d s\left(\begin{array}{l}
1 \\
0
\end{array}\right) \\
& =\phi(L ; \lambda) \int_{-L}^{L}\left(\begin{array}{c}
\tilde{u}(s) u(s) w(s) \\
-u^{2}(s) w(s)
\end{array}\right) d s .
\end{aligned}
$$

Jika $\lambda=\lambda_{0}$ adalah nilai eigen, maka $E\left(\lambda_{0}\right)=0$ (dari Teorema 4.1). Hal ini berarti

$$
\phi\left(L ; \lambda_{0}\right)\left(\begin{array}{c}
1 \\
0
\end{array}\right)=\hat{c}\left(\begin{array}{c}
-\frac{b_{2}}{p(L)} \\
a_{2}
\end{array}\right), \hat{c} \neq 0 .
$$


Akibatnya,

$$
\begin{aligned}
\left.\frac{\partial E(\lambda)}{\partial \lambda}\right|_{\lambda=\lambda_{0}} & =\frac{\partial}{\partial \lambda}\left(\operatorname{det}\left(\phi\left(L ; \lambda_{0}\right)\left(\begin{array}{c}
1 \\
0
\end{array}\right) \begin{array}{c}
-\frac{b_{2}}{p(L)} \\
a_{2}
\end{array}\right)\right) \\
& =\operatorname{det}\left(\frac{\partial}{\partial \lambda} \phi\left(L ; \lambda_{0}\right)\left(\begin{array}{l}
1 \\
0
\end{array}\right) \frac{1}{\hat{c}} \phi\left(L ; \lambda_{0}\right)\left(\begin{array}{l}
1 \\
0
\end{array}\right)\right) \\
& =\frac{1}{\hat{c}} \operatorname{det}\left(\phi\left(L ; \lambda_{0}\right)\right) \operatorname{det}\left(\begin{array}{cc}
\int_{-L}^{L} w(s) \tilde{u}(s) d s & 1 \\
-\int_{-L}^{L} w(s)\left(u^{2}(s)\right) d s & 0
\end{array}\right) \\
& =\frac{1}{\hat{c}} \int_{-L}^{L} w(s)\left(u^{2}(s)\right) d s .
\end{aligned}
$$

Perhatikan bahwa $w(x)>0$ dan $u(x) \neq 0$ bernilai riil (karena $p, q, w$ bernilai riil). Dengan demikian

$$
\left.\frac{\partial E(\lambda)}{\partial \lambda}\right|_{\lambda=\lambda_{0}} \neq 0
$$

\section{Aplikasi pada Pelacakan Nilai Eigen}

Pada subbab ini akan dibahas aplikasi fungsi Evans pada pelacakan nilai eigen dari masalah Sturm-Liouville untuk kasus khusus berikut:

$$
p(x)=w(x)=1, \quad q(x)=0, \quad a_{1}=a_{2}=1, \quad b_{1}=b_{2}=0 .
$$

Dengan demikian masalah Sturm-Liouville menjadi

$$
-\frac{d^{2} y}{d x^{2}}+V(x) y=\lambda y
$$

dengan syarat batas

$$
y(-L)=y(L)=0 .
$$

Perhatikan bahwa masalah Sturm-Liouville di atas, berdasarkan penjelasan pada bagian 3, dapat dinyatakan dalam sistem berikut:

$$
\frac{\partial}{\partial x} \phi=\left(\begin{array}{cc}
0 & 1 \\
-\lambda & 0
\end{array}\right) \phi, \quad \phi(-L ; \lambda)=\left(\begin{array}{cc}
0 & -1 \\
1 & 0
\end{array}\right) .
$$

Matriks solusi fundamental untuk sistem di atas diperoleh

$$
\phi(x ; \lambda)=\left(\begin{array}{cc}
\frac{\sin (\sqrt{\lambda}(x+L)}{\sqrt{\lambda}} & -\cos (\sqrt{\lambda}(x+L)) \\
\cos (\sqrt{\lambda}(x+L)) & \sqrt{\lambda} \sin (\sqrt{\lambda}(x+L))
\end{array}\right) .
$$

Dengan demikian fungsi Evans yang diperoleh adalah

$$
\begin{aligned}
E(\lambda) & =\operatorname{det}\left(\phi(L ; \lambda)\left(\begin{array}{l}
1 \\
0
\end{array}\right) \begin{array}{c}
-\frac{b_{2}}{p(L)} \\
a_{2}
\end{array}\right) \\
& =\frac{\sin (2 L \sqrt{\lambda})}{\sqrt{\lambda}} .
\end{aligned}
$$


Perhatikan bahwa $E(\lambda)=0, \lambda \neq 0$, terjadi pada saat

$$
\lambda=\frac{\pi^{2} n^{2}}{4 L^{2}}, n \in \mathbb{N} .
$$

Jika $L=\frac{\pi}{2}$ maka $\lambda=n^{2}, n \in \mathbb{N}$. Jadi $\lambda \in\{1,4,9,16, \cdots\}$.

\section{Kesimpulan}

Pada paper ini telah dikonstruksi fungsi Evans pada masalah Sturm-Liouville. Masalah Sturm-Liouville sendiri merupakan masalah nilai eigen yang muncul ketika metode pemisahan variabel digunakan dalam menyelesaikan suatu persamaan diferensial parsial linier orde 2, di antaranya persamaan panas, persamaan gelombang, dan persamaan Laplace. Beberapa sifat fungsi Evans yang telah dibahas dalam paper ini adalah:

(1) Nilai nol dari fungsi Evans berkaitan dengan nilai eigen pada masalah SturmLiouville.

(2) Fungsi Evans analitik untuk semua nilai eigen yang bernilai kompleks.

(3) Fungsi Evans mempunyai simple zeros ketika koefisien-koefisien pada masalah Sturm-Liouville bernilai riil dan positif.

Pada paper ini juga telah dibahas aplikasi fungsi Evans pada pelacakan nilai eigen dari kasus khusus masalah Sturm-Liouville.

\section{Ucapan Terima kasih}

Penulis mengucapkan terima kasih kepada Ibu Dr. Lyra Yulianti, Ibu Nova Noliza Bakar M.Si, Bapak Zulakmal, M.Si dan Bapak Dr. Dodi Devianto yang telah memberikan masukan dan saran sehingga paper ini dapat diselesaikan dengan baik.

\section{Daftar Pustaka}

[1] Lewis, Benjamin. 2012. Tracking the Movement of Eigenvalues Via a Corresponding Evans Function. SIAM. 1 - 15

[2] Mathews, J.,R. Howell. 2006. Complex Analysis for Mathematics and Engineering, Fifth edition. Jones and Bartlett Publisher, New York.

[3] Sheng Gong. 2000. Concise Complex Analysis. World Scientific Publishing Co. Pte. Ltd., London.

[4] Boyce, William.E, Richard C. DiPrima. 2009. Elementary Differential Equations and Boundary Value Problems. John Wiley and Sons, New Jersey.

[5] Churchill, Ruell V., James Ward Brown. DiPrima. 1996. Complex Variables and Application. McGraw-Hill, Inc, New York.

[6] Howard, Anton. 1998. Aljabar Linier Elementer. Edisi kelima. Erlangga, Jakarta. 